\title{
Use of multi-criteria decision-aids for risk zoning and management of large area subjected to mining-induced hazards
}

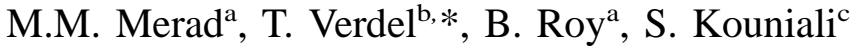 \\ ${ }^{a}$ LAMSADE, University of Paris IX-Dauphine, Paris, Cedex F-75775, France \\ ${ }^{\mathrm{b}}$ LAEGO, Ecole des Mines-Nancy, Parc de Saurupt, Nancy, Cedex F-54042, France

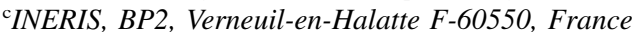

Received 26 April 2003; received in revised form 19 July 2003; accepted 29 August 2003

\begin{abstract}
The end of iron-mining operations in France's Lorraine region has raised the problem of post-mining management. Collapses and subsidence have recently occurred in this region, which focused on the necessity to develop a specific methodology for risk zoning. The proposed methodology is based on the multi-criteria decision-aid approach called 'ELECTRE TRI', with aim to assign zones at risk into predefined classes. It allows experts opinions, qualitative and quantitative criteria and uncertainties to be taken into account.
\end{abstract}

(C) 2003 Elsevier Ltd. All rights reserved.

Keywords: Risk; Public safety; Subsidence; Uncertainty; Multi-criteria

\section{Introduction}

Mine subsidence events have recently occurred in the Lorraine iron-mining basin (North-eastern France) causing major damages to surface buildings and infrastructures (Deck et al., 2003). These events have raised widespread awareness of the severity of human, technical, financial and legal risks due to the end of mining activities. The Lorraine iron-mining basin, which covers a surface area of $1150 \mathrm{~km}^{2}$, had been mined for more than a century (Varoquaux, 1995) up until 1997 by reliance upon the 'room and pillar' caving method under urban areas in order to prevent the ground from subsidence. This 'technical' prevention strategy, however, has failed several times throughout history and, consequently, it has now become necessary to establish a "managerial' prevention strategy based on risk analysis. According to natural hazard theory, risk appears wherever and whenever assets are subjected to hazards; it is usually defined as 'the expected potential loss due to a particular hazard for a given area and reference period' (UN, 1992) and can be mathematically defined as the combination of hazard and vulnerability (UN, 1992;

\footnotetext{
*Corresponding author.

E-mail address: thierry.verdel@mines.inpl-nancy.fr (T. Verdel)
}

Varnes, 1984). In France, Risk Prevention Plans (RPPs) have been adopted to control risks due to ground movement (MATE, 1999). Such plans consist of producing four principal outputs: an informative report about the natural phenomena; a hazard map (gives the contours of the area subjected to given levels of hazards); an assets evaluation (whether formalized or not on a map); and a risk map (superimposition of hazard and assets maps). In practice, RPPs are commonly prepared using the 'typical configurations' method (Didier, 1999), which entails identifying within the study area a limited number of rupture scenarios, called 'configurations'. A hazard level is then ascribed to each configuration. Afterwards, homogeneous zones are established according to these configurations in order to produce a hazard map. Despite the advantages associated with the 'typical configurations' method, which serves to formalize expert approach, some imperfections still remain. Firstly, when this method is placed into practice, it only provides a hazard map, not a risk map. Secondly, the hazard map established is extremely dependent upon the knowledge and experience held by the engineer in charge. Thirdly, the method has been developed for low extended area (quarries) rather than large extended area (mining basin). Lastly, uncertainties, inaccuracies and 


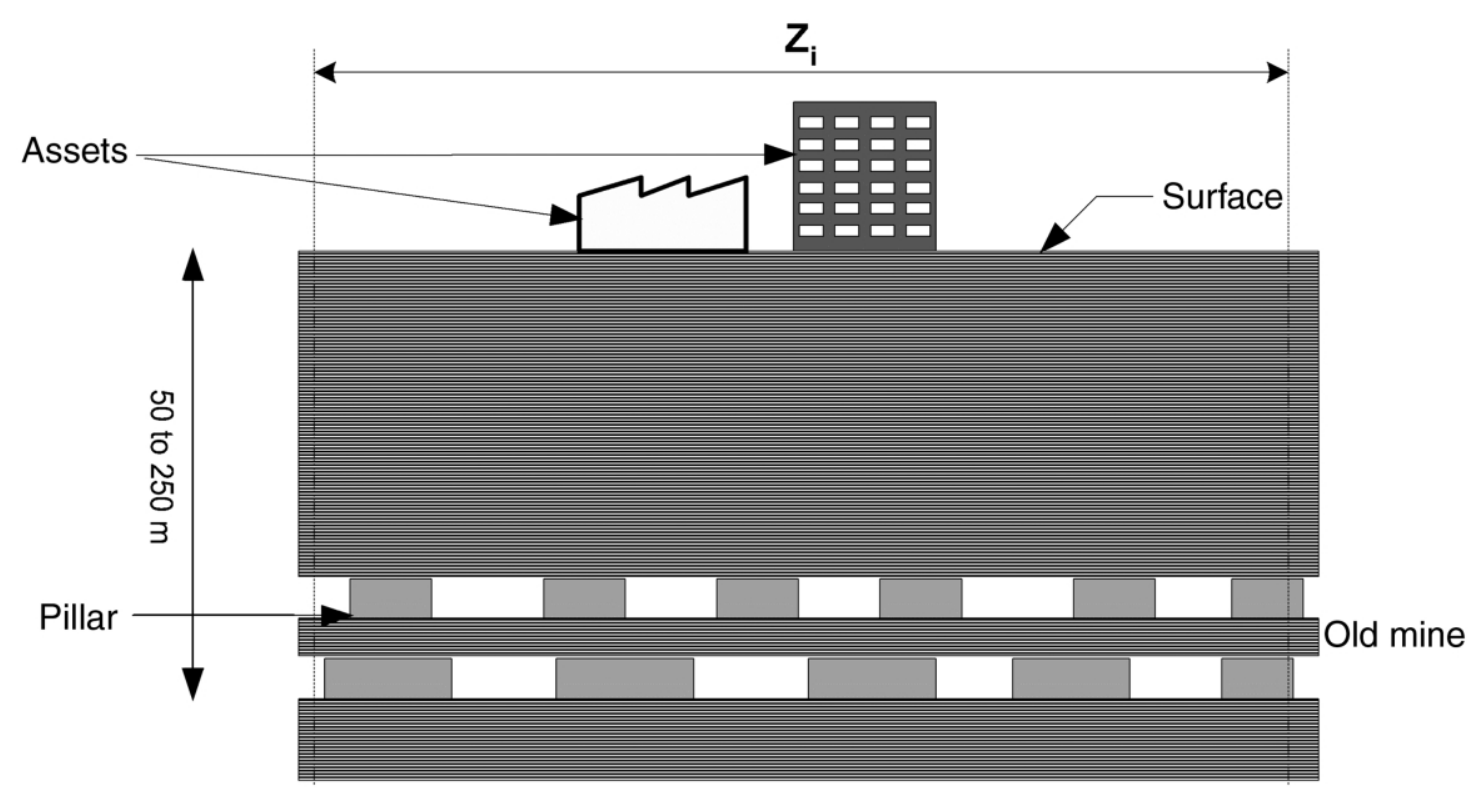

Fig. 1. Risk induced by the presence of a mine and assets on the ground surface.
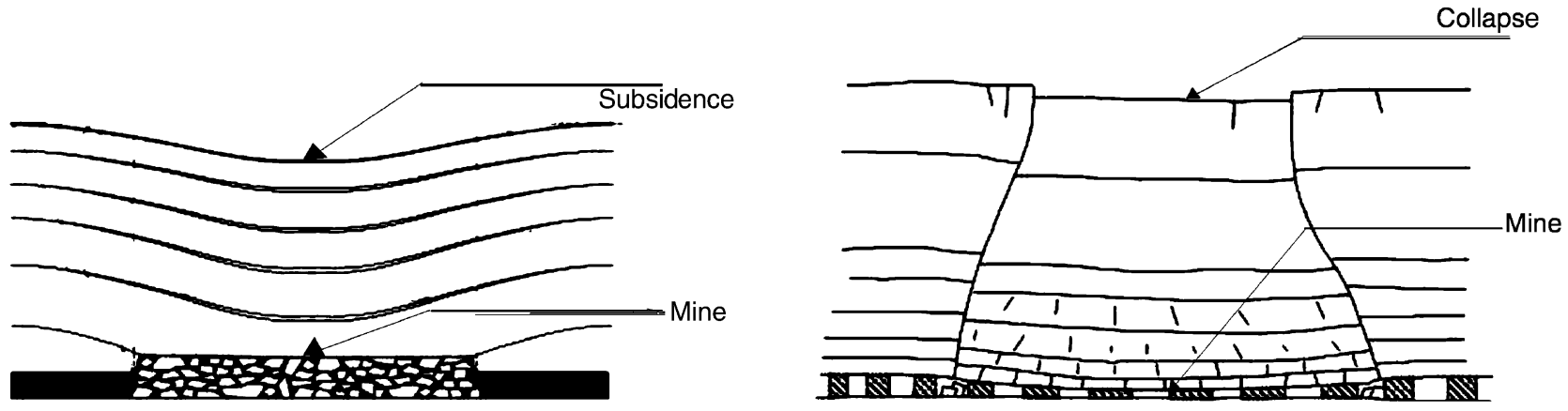

Fig. 2. Surface impacts due to mining collapse.

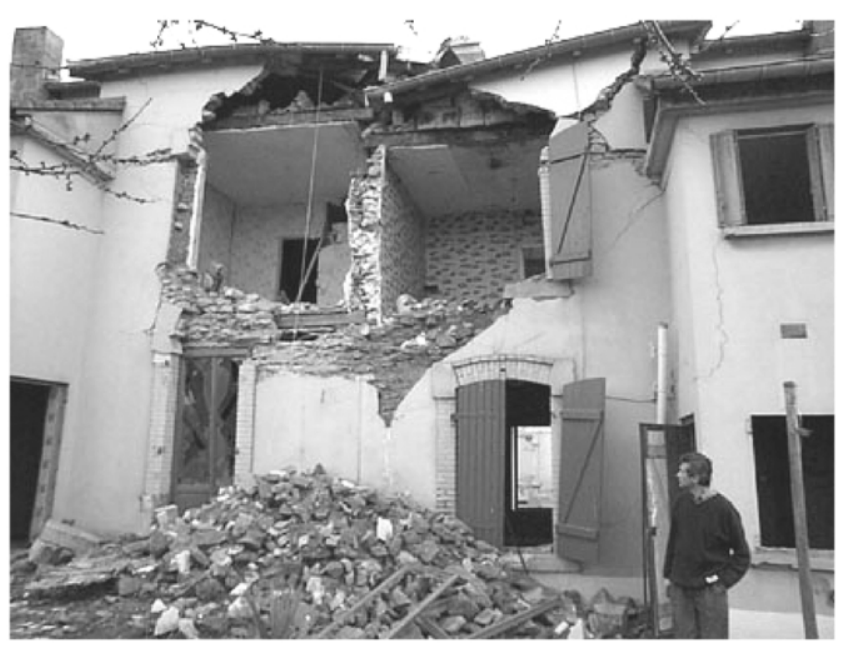

Fig. 3. Example of a house damaged by mining subsidence (Auboué, France, 1996). incomplete knowledge are not explicitly identified nor taken into account. In order to overcome these shortcomings, we are proposing herein another method, based on a multi-criteria decision-aid approach, for prioritising zones at risk.

\section{Multi-criteria, decision-aid methods for risk analysis}

The zones at risk studied lie in urbanized areas within France's Lorraine region, which had been mined using the 'rooms and pillars' method. These zones span a land area of over $20 \mathrm{~km}^{2}$. The 'rooms and pillars' method consists of extracting ore in the rooms and then leaving pillars to support the weight of the overlying ground (see Fig. 1).

Mining works, however, can present a danger to people and buildings when pillars fail to withstand ground loads. Such a rupture can induce a gradual settlement of the surface, called subsidence (Fig. 2a), 


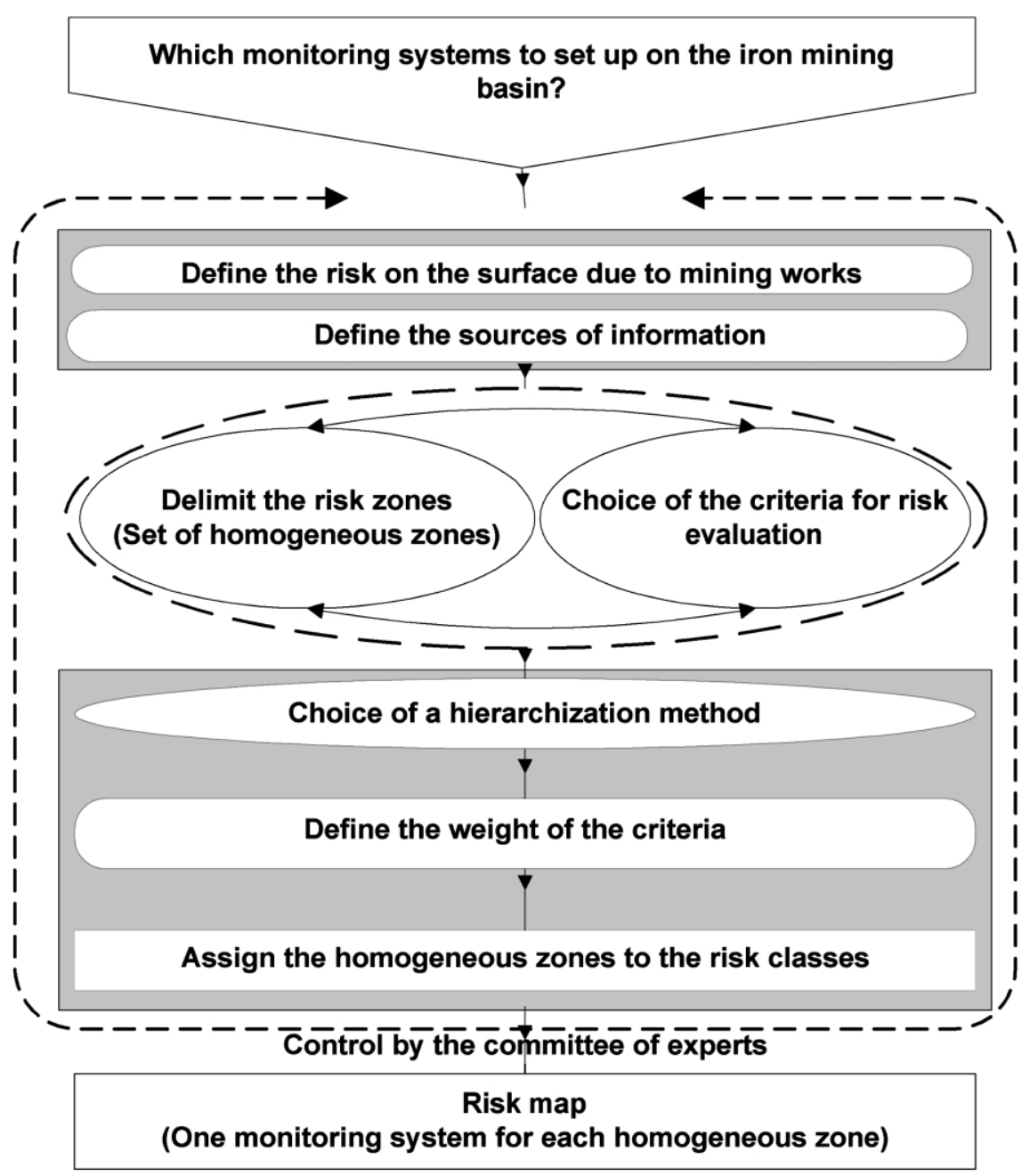

Fig. 4. General principle underlying the chosen risk analysis method.

or a more brutal settlement called collapse (Fig. 2b), which consists in an instantaneous drop of the entire overlying ground (Whittaker and Reddish, 1989). These phenomena may, in certain instances, produce dramatic consequences (ruin) on surface buildings (Fig. 3) and infrastructures.

Within such a context, risk analysis proves to be a complex decision-making problem where the available information is uncertain (missing information, such as geological data) and imprecise (mining works maps) and where knowledge is incomplete (e.g. soil-structure interaction). Multi-criteria, decision-aid methods can help overcome these limitations because they basically include mathematical mechanisms to manage these aspects. One such method called ELECTRE (Roy, 1985; Roy and Bouyssou, 1993) is widely used in France and Europe for resolving decision-type problems involving institutions and experts (Roy and Bouyssou, 1993). We would like to emphasize the feasibility, advantages and difficulties encountered when adapting the ELECTRE method to the prioritisation of zones subjected to mining subsidence or collapse. The application of the proposed methodology requires the assistance of a committee of experts to handle complexity issues. The general principle underlying this methodology has been depicted in Fig. 4.

The committee of experts called upon for the present purposes has defined four risk classes, given that an appropriate monitoring device must be set up for the identified zones as a function of estimated risk level. By convention, Class 1 corresponds to the highest risk level and Class 4 to the lowest. A permanent monitoring system must be introduced for all Class 1 zones, while only reference levelling (topographic surveys) is required for Class 4 zones (see Table 1). The aim of this method is to identify and categorize homogeneous zones into these four predefined risk classes.

The first step consists in selecting the studied risk (collapse or subsidence) among those available (collapse, subsidence, pollution, sinkholes, slope instabilities, etc.). This choice will then influence the second step, which entails choosing the criteria applied to provide information on the risk and, similarly, to identify homogeneous zones over the study area; homogeneous 
Table 1

Monitoring measures for the four risk classes

\begin{tabular}{ll}
\hline Risk classes & Monitoring measures \\
\hline 1 & $\begin{array}{l}\text { Long term continuous monitoring based on the recording of underground } \\
\text { microsismic activity. }\end{array}$ \\
2 & In depth investigation including geological boring if necessary. \\
3 & Reference and annual levelling. \\
4 & Reference levelling. \\
\hline
\end{tabular}

zones are those whose intrinsic characteristics (i.e. values of the selected criteria) are identical (see Figs. 5 and 6). The last step consists of choosing a prioritisation method for analysing these homogeneous zones, i.e. moving from a partial evaluation of the zone on each criterion to a global evaluation of the entire zone (level of risk) (Fig. 7) based on all criteria.

In the following sections, we will examine in greater detail how risk zones are selected, how a set (family) of criteria and sets of weights are defined, and how the 'ELECTRE TRI' method is integrated for prioritising zones at risk.

\section{Selection of zones at risk and choice of evaluation criteria and weighting sets}

The procedure used to select zones at risk is illustrated in Fig. 8. In addition to this schematic approach, the zones must satisfy two selection tests defined by the committee of experts: (1) the stress applied on pillars must be greater than or equal to $7.5 \mathrm{MPa}$ (no pillar rupture is expected below this value); (2) zone width must exceed $0.9 \times H$, where $H$ represents depth from the operating wall (no significant effects on surface below this value). If these conditions are not fulfilled, it is considered that the selected zone presents no danger and monitoring is not necessary in such cases. The same conclusions are valid for zones with no surface assets.

Let $\mathrm{Z}$ be the set of zones at risk and $\mathrm{Z}_{i}$ be a zone such that $\mathrm{Z}_{i} \in \mathrm{Z}$, with $i=1, \ldots, m$, where $m$ represents the number of zones.

The data available for each zone can be either quantitative (stress applied to pillars, depth, zone extent, etc.) or qualitative (presence of faults, superposition of

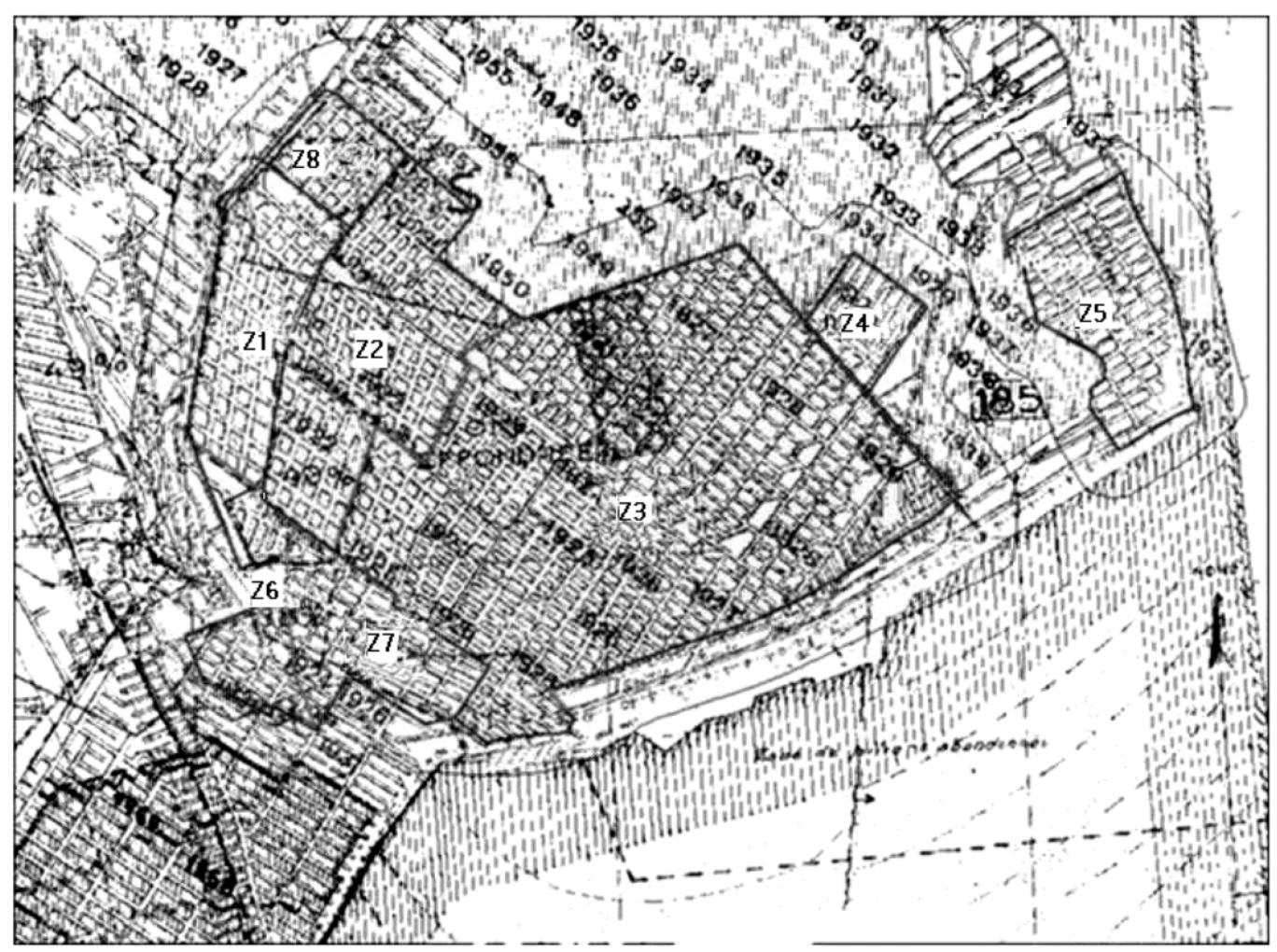

Fig. 5. Mining works map divided into homogeneous zones $\left(Z_{1}\right.$ to $\left.Z_{8}\right)$. 


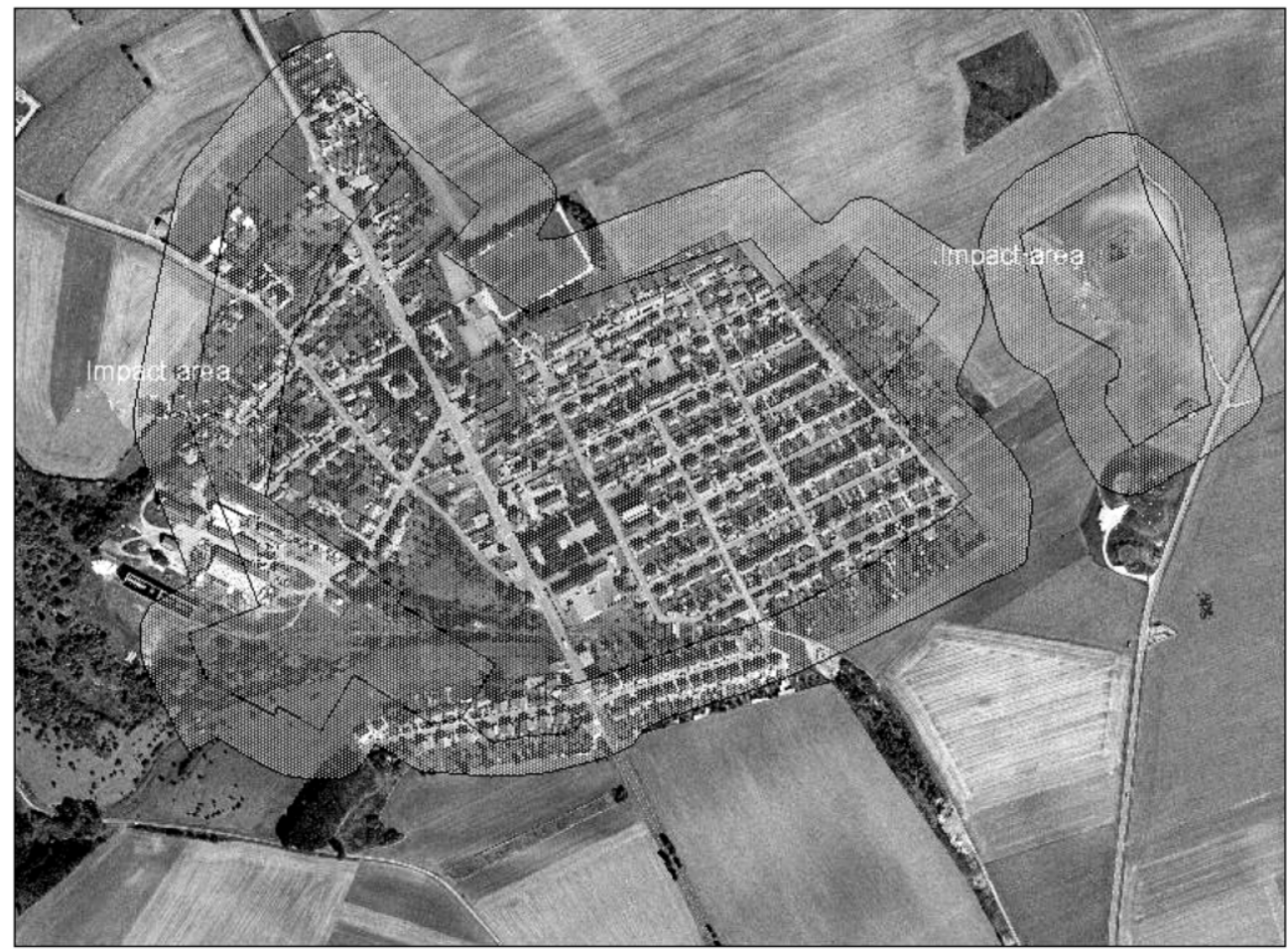

Fig. 6. Aerial photograph of assets above mining works shown on Fig. 5, with the contours of zones $Z_{1}$ to $Z_{8}$.

pillars, sensitivity to flooding, etc.). The risk due to mining subsidence is therefore represented in a multicriteria form. Due to the extent of the basin studied and the objectives inherent in risk mapping, relevant data are synthesized through a family of criteria that may be defined on each zone selected for the prioritisation study.

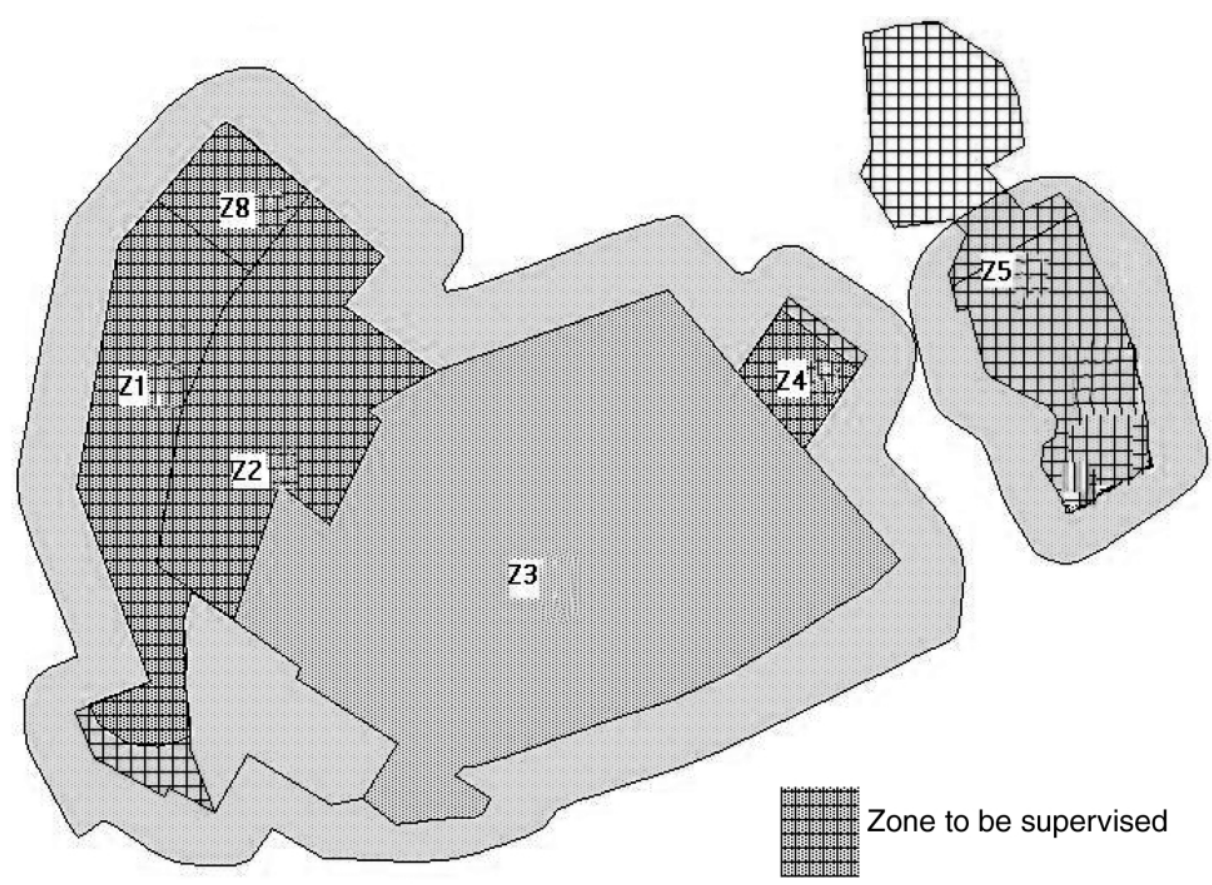

Fig. 7. Results of the risk analysis by zone. 


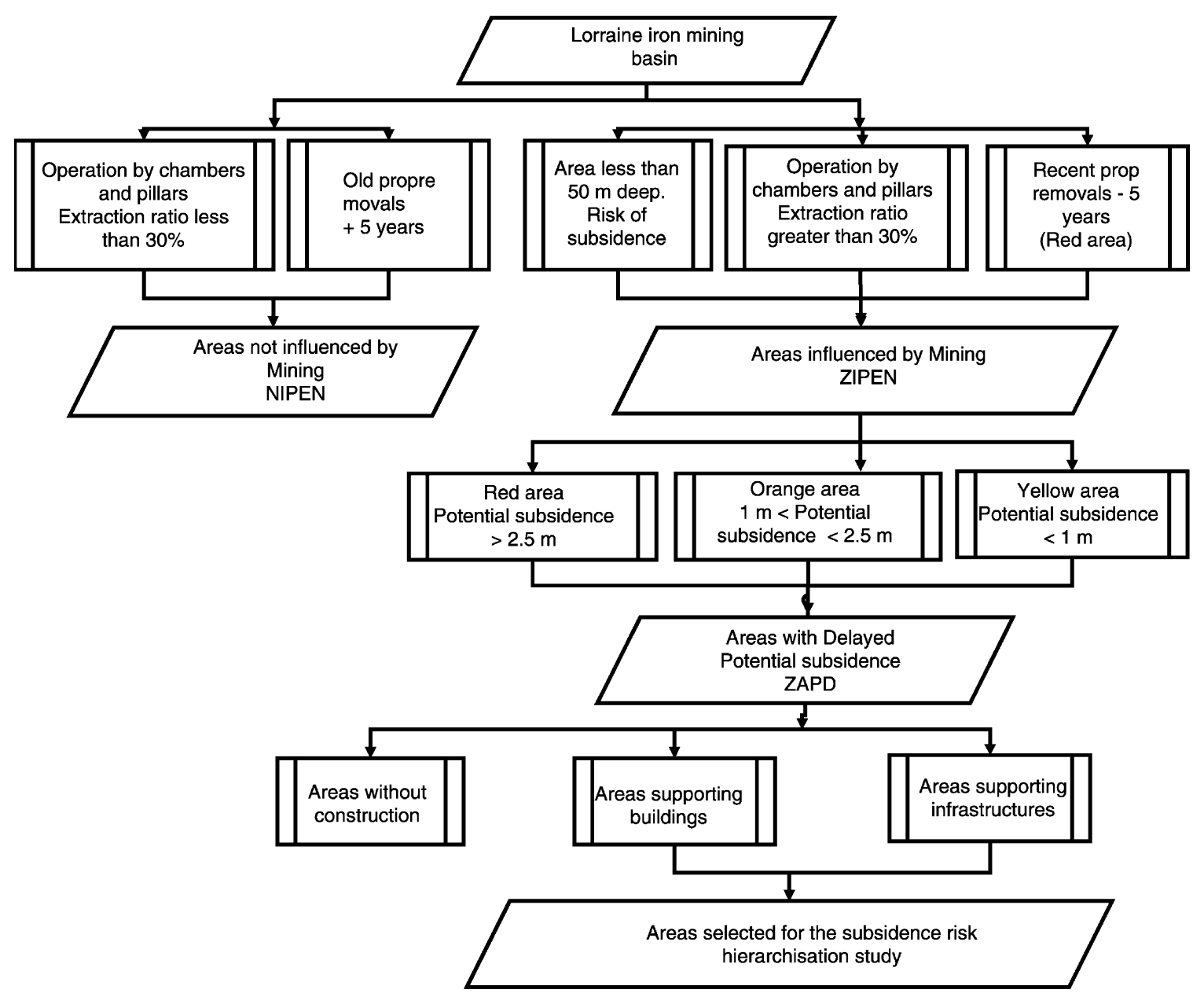

Fig. 8. Identification and selection of zones for prioritisation.

These criteria are implemented in conjunction with and under the supervision of a committee of experts. These criteria taken as a whole form a consistent family (Roy, 1985), meaning that:

- Two zones with identical criteria values are assigned to the same risk class: the criteria family is said to be exhaustive;

- A zone on which the value on one criterion is reduced (in terms of decreasing risk) cannot be assigned to a lower class (higher risk) than that initially assigned: the criteria family is said to be consistent;

- A zone cannot be assigned to a class when one criterion is removed from the criteria family: the criteria family is said to be non-redundant.

The various criteria used have been grouped into two headings: 'susceptibility of the mine to collapse' and 'surface sensitivity' (see Table 1). The first refers to the 'probability of rupture' and the second to both the 'intensity of the rupture' and the 'value and vulnerability of assets'.
Let $g_{j}$ be a criterion within the family of criteria, where $j=1, \ldots n$ and $n$ is the number of criteria. A qualitative or quantitative scale is then defined for each criterion $g_{j}$. The quantitative criteria $g_{1.1}, g_{2.1}, g_{2.2}, g_{2.3}$ and $g_{2.4}$ (Table 2) are evaluated in their own units. For example, $g_{1.1}$, which denotes the stress applied on pillars, is given in MPa and $g_{2.2}$, representing depth, in $\mathrm{m}$. The remaining criteria are qualitative and expressed in various appropriate scales. The 'superimposition of pillars' criterion can take the following status: (0) a mined layer; (10) two layers with well superimposed pillars or a thick intermediate layer $(\geq 7 \mathrm{~m})$; (20) two layers with poorly-superimposed pillars or a thin intermediate layer $(<7 \mathrm{~m})$. This codification $(0,10,20)$ does not connote any numerical significance (Roy, 1985) and other coding systems, such as $(6,7,8)$, could also be used.

Two types of surface assets are considered for each zone $\mathrm{Z}_{i}$ : buildings and infrastructures. This distinction makes it necessary to apply different criteria to evaluate the risk for $Z_{i}$ according to surface occupancy. If $Z_{i}$ is a zone with buildings, then the criteria used would be 
Table 2

Family of criteria

\begin{tabular}{|c|c|c|c|c|c|}
\hline No. & Criterion & Nature & Unit & Codes & $\begin{array}{l}\text { Direction of } \\
\text { risk increase }\end{array}$ \\
\hline \multicolumn{6}{|c|}{ G1. Susceptibility of the mine to collapse } \\
\hline & & & & $k \times \frac{0.25 \times H}{}$ & \\
\hline$g_{1.1}$ & $\begin{array}{l}\text { Corrected mean stress } \\
\text { applied on pillars }\end{array}$ & Quanti. & MPa & $k \times \overline{1-\tau}$ & + \\
\hline$g_{1.2}$ & Existence of fault & Quali. & (code) & 0: no; 10: yes. & + \\
\hline$g_{1.3}$ & Superimposition of pillars & Quali. & (code) & $\begin{array}{l}\text { 0: only one mined layer; } \\
\text { 10: two well superimposed layers } \\
\text { or thick intermediate layer }(\geq 7 \mathrm{~m}) \text {; } \\
\text { 40: two bad superimposed layers } \\
\text { or thin intermediate layer }(<7 \mathrm{~m}) \text {. }\end{array}$ & + \\
\hline$g_{1.4}$ & $\begin{array}{l}\text { Size and regularity of } \\
\text { pillars }\end{array}$ & Quali. & (code) & $\begin{array}{l}\text { 0: large pillars; } \\
\text { 10: small regular pillars; } \\
\text { 20: small irregular pillars. }\end{array}$ & + \\
\hline$g_{1.5}$ & $\begin{array}{l}\text { Sensitivity of rock to } \\
\text { flooding (depending on the } \\
\text { rock type) }\end{array}$ & Quali. & (code) & $\begin{array}{l}\text { 0: no sensitivity; } \\
\text { 10: sensitive; } \\
\text { 20: very sensitive; } \\
\text { 30: highly sensitive. }\end{array}$ & + \\
\hline \multicolumn{6}{|c|}{ G2. Surface sensitivity } \\
\hline$g_{2.1}$ & Depth of the top mined layer & Quanti. & $\mathrm{m}$ & Given on maps. Called H. & - \\
\hline$g_{2.2}$ & $\begin{array}{l}\text { Maximum expected } \\
\text { subsidence }\end{array}$ & Quanti. & $\mathrm{m}$ & $\begin{array}{l}\text { Deduced from subsidence models. } \\
\text { Called } A_{m} \text {. }\end{array}$ & + \\
\hline$g_{2.3}$ & $\begin{array}{l}\text { Expected surface } \\
\text { deformation (deduced from } \\
\text { subsidence models) }\end{array}$ & Quanti. & $\mathrm{mm} / \mathrm{m}$ & $\varepsilon_{\max }=1.5 \times \frac{A_{m}}{H}$ & + \\
\hline$g_{2.4}$ & Zone extent & Quanti. & $\mathrm{km}^{2}$ & Given on maps. & + \\
\hline$g_{2.5 .1}$ & Vulnerability of building & Quali. & (code) & $\begin{array}{l}\text { 5: commercial zones; } \\
\text { 10: isolated houses; } \\
\text { 20: grouped houses; } \\
\text { 30: long buildings; } \\
\text { 40: urban area. }\end{array}$ & + \\
\hline$g_{2.5 .2}$ & Vulnerability of roads & Quali. & (code) & $\begin{array}{l}\text { 0: no road; } \\
\text { 10: local road; } \\
\text { 20: national road; } \\
\text { 30: highway. }\end{array}$ & + \\
\hline$g_{2.5 .3}$ & Vulnerability of railways & Quali. & (code) & $\begin{array}{l}\text { 0: no line; } \\
\text { 10: standard line; } \\
\text { 20: speed line; } \\
\text { 30: high speed line. }\end{array}$ & + \\
\hline$g_{2.5 .4}$ & Vulnerability of bridges & Quali. & (code) & $\begin{array}{l}0 \text { : no bridge; } \\
\text { 10: presence of bridge. }\end{array}$ & + \\
\hline$g_{2.5 .5}$ & $\begin{array}{l}\text { Vulnerability of various } \\
\text { networks }\end{array}$ & Quali. & (code) & $\begin{array}{l}\text { 0: no network; } \\
\text { 10: electricity network; } \\
\text { 20: water network; } \\
\text { 30: gas network. }\end{array}$ & + \\
\hline
\end{tabular}

$g_{1.1}$ to $g_{1.5}$ and $g_{2.1}$ to $g_{2.5 .1}$; if, however, $Z_{i}$ is a zone with infrastructures, the criteria would be $g_{1.1}$ to $g_{1.5}$, $g_{2.1}$ to $g_{2.4}$ and $g_{2.5 .2}$ to $g_{2.5 .5}$. Table 3 gives a detailed example of the evaluation of a zone with buildings.

Note that due to the ultimate 'Public safety' purpose of this risk analysis, buildings have been considered more sensitive than infrastructures. If both buildings and infrastructures are present on a given surface zone $Z_{i}$, then the criteria for zones with buildings are to be employed.

\section{From partial to global risk evaluation}

\subsection{Choice of a method for prioritising zones at risk}

Several multi-criteria, decision-aid methods can be used to progress from a partial evaluation of the risk on 
Table 3:

Example of information provided on the zone Z9 (see table 5) for all prioritisation criteria

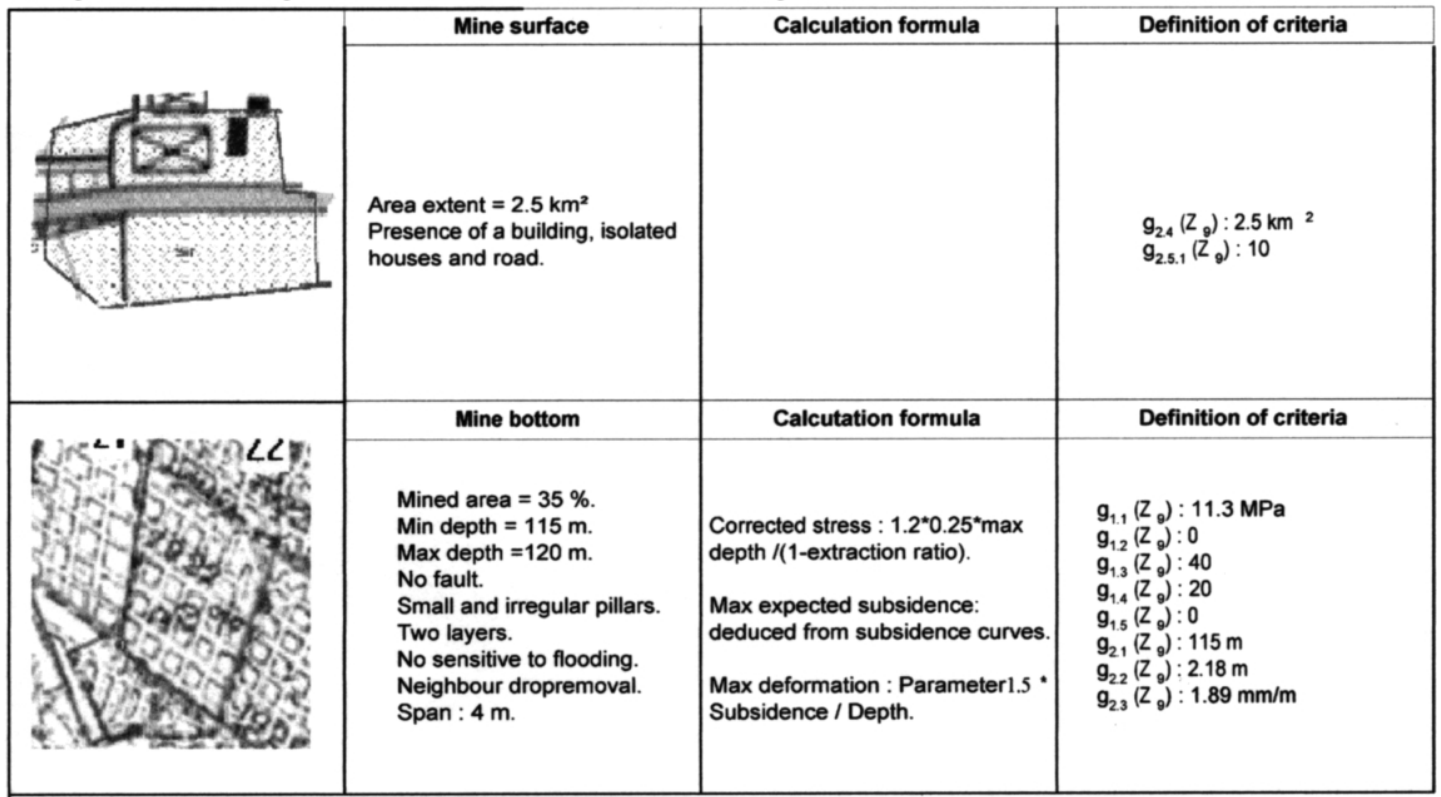

each criterion $g_{i}$ to a global risk evaluation based on all criteria (Roy, 1985; Roy and Bouyssou, 1993). One of the most frequently used methods is the "weighted mean

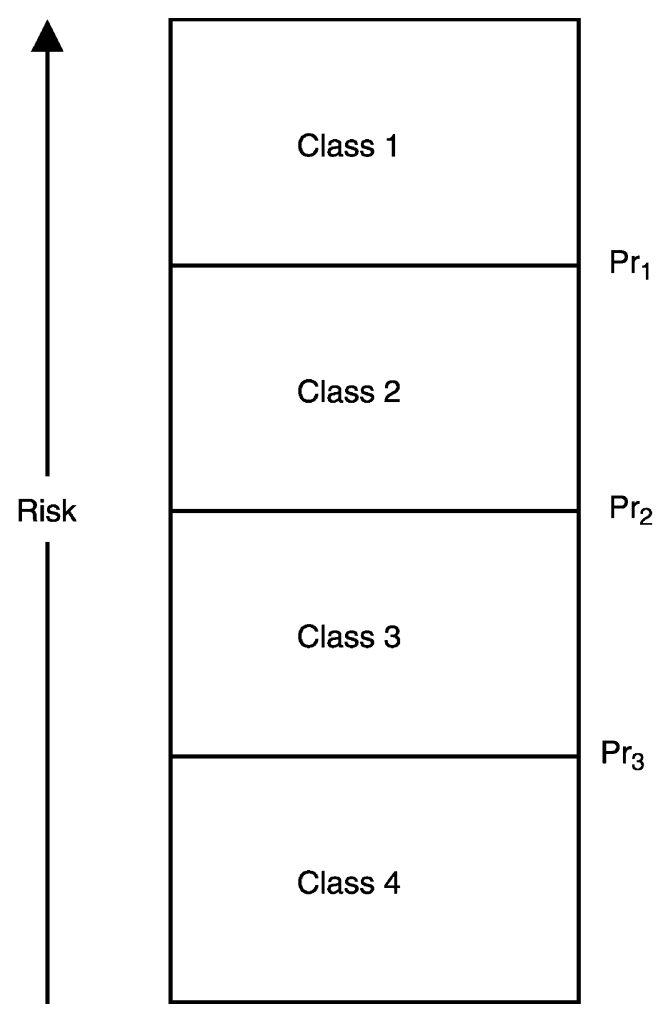

Fig. 9. Four risk classes separated by three low profiles $\operatorname{Pr}_{h}$. method', which provides a complete order and enables differentiating the weight of criteria. It is possible, for example, to ascribe a particular criterion $g_{j}$ with a greater weight, hence a greater role in determining the class assignment. This method, however, imposes certain strict constraints, such as the numerical evaluation on each criterion $g_{j}$ and leads to compensation effects since equal evaluation differences correspond to equal risk variation measurements (Roy, 1985). Furthermore, the weighted mean method does not easily accommodate uncertainties and inaccuracies. These elements make 'ELECTRE'-type methods and 'ELECTRE TRI' in particular, applicable. ELECTRE TRI is appropriated to sort zones $Z_{i}$ into four predefined, mutually exclusive and ordered risk classes (Roy, 1985; Yu, 1992).

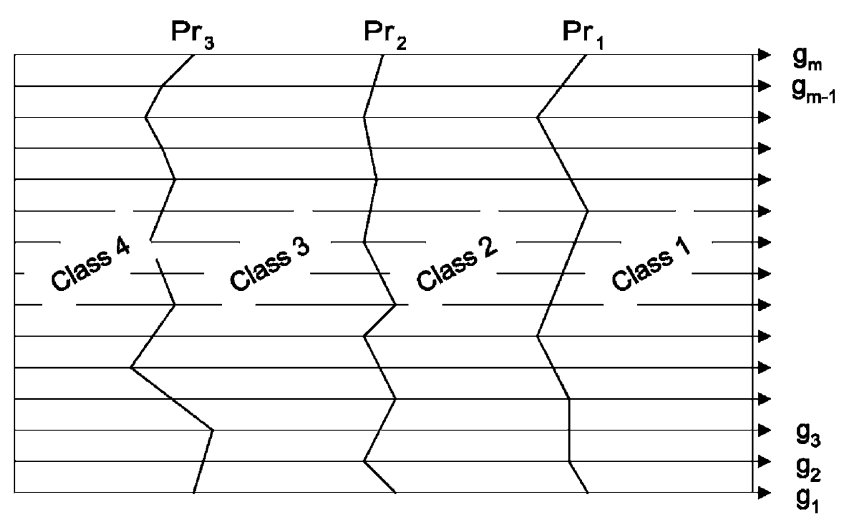

Fig. 10. Principal position of class profiles $\operatorname{Pr}_{h}$ on each criterion $g_{j}$. 


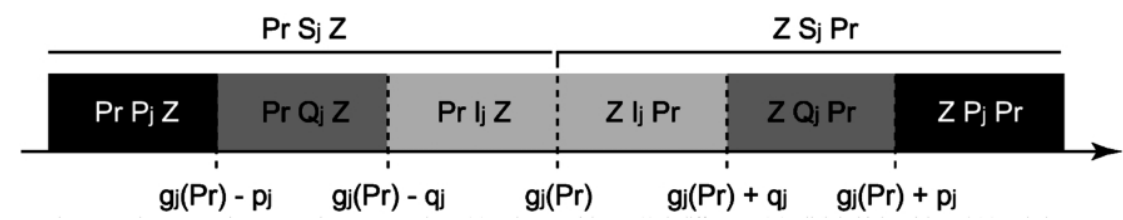

Fig. 11. Three comparison set-ups between $Z_{i}$ and $\operatorname{Pr}_{h}$.

Each risk class $h(h \in\{1,2,3,4\})$ is delimited by a threshold profile $\operatorname{Pr}_{h}$ (see Fig. 9). A class profile $\operatorname{Pr}_{h}$ is a virtual zone representing an entry standard into a risk class. Each profile $\operatorname{Pr}_{h}$ takes a value on each criterion $g_{j}$ (Fig. 10). Since Class 1 is the highest risk class, profile $\operatorname{Pr}_{1}$ 'displays a risk at least as high as' $\operatorname{Pr}_{2}$ for every criterion. This is written $\operatorname{Pr}_{1} \mathrm{~S} \operatorname{Pr}_{2}$. In turn, $\operatorname{Pr}_{2}$ 'displays a risk at least as high as' $\operatorname{Pr}_{3}$ for every criterion $\left(\mathrm{Pr}_{2} \mathrm{~S} \mathrm{Pr}_{3}\right)$.

For each criterion $g_{j}$ it is possible to compare a zone $Z_{i}$ with a profile $\operatorname{Pr}_{h}$. This is called a partial comparison. It is thus partially possible to determine if zone $Z_{i}$ lies within risk class $h$. In this comparison process, uncertainty on criteria values can be taken into account (with ELECTRE TRI) through two thresholds: the indifference threshold $q_{j}$ and the preference threshold $p_{j}$ (see Appendix A and Fig. 11).

In order to assign zones to risk classes (to go from a partial assignment to a global assignment), we have chosen the 'ELECTRE TRI' pseudo-disjunctive procedure (see Appendix A). This procedure is based on the calculation of a credibility index $\sigma$ and its comparison with a parameter $\lambda$. Intuitively, $\lambda$ represents a desired majority of decision-making criteria (Roy and Bouyssou, 1993). There are only three possible situations (Yu, 1992):

1. Indifference: $\sigma\left(\mathrm{Z}_{i}, \operatorname{Pr}_{h}\right) \geq \lambda$ and $\sigma\left(\operatorname{Pr}_{h}, \mathrm{Z}_{i}\right) \geq \lambda$, which is denoted $Z_{i} I \operatorname{Pr}_{h}$ (with $Z_{i}$ and $\operatorname{Pr}_{h}$ being equivalent);

2. Strict preference (risk strictly higher than):

2. $1 \sigma\left(\mathrm{Z}_{i}, \operatorname{Pr}_{h}\right) \geq \lambda$ and $\sigma\left(\operatorname{Pr}_{h}, Z_{i}\right)<\lambda$, which is denoted

$\mathrm{Z}_{i} \mathrm{P} \operatorname{Pr}_{h}\left(\mathrm{Z}_{i}\right.$ exhibits greater risk than $\left.\operatorname{Pr}_{h}\right)$;

2.2 $\sigma\left(\operatorname{Pr}_{h}, Z_{i}\right) \geq \lambda$ and $\sigma\left(Z_{i}, \operatorname{Pr}_{h}\right)<\lambda$, which is denoted

$\operatorname{Pr}_{h} \mathrm{P} \mathrm{Z}_{i}\left(\operatorname{Pr}_{h}\right.$ exhibits greater risk than $\left.\mathrm{Z}_{i}\right)$;

3. Incomparability: $\sigma\left(\mathrm{Z}_{i}, \operatorname{Pr}_{h}\right)<\lambda$ and $\sigma\left(\operatorname{Pr}_{h}, Z_{i}\right)<\lambda$, which is denoted $Z_{i} R \operatorname{Pr}_{h}$, meaning that $Z_{i}$ and $\operatorname{Pr}_{h}$ are incomparable.

In cases where $Z_{i} P \operatorname{Pr}_{h}$ or $Z_{i} \mathrm{I} \mathrm{Pr}_{h}, Z_{i}$ is assigned to the class with $\operatorname{Pr}_{h}$ representing the lower profile of the class $h$. The use of the pseudo-disjunctive procedure within the ELECTRE TRI method implies that when comparison between a zone and a profile proves impossible (due to incomparability), the zone also gets assigned to the class where $\operatorname{Pr}_{h}$ is the lower profile.

For each zone, the assignment procedure starts by a comparison with the lower profile $\left(\mathrm{Pr}_{3}\right)$ and ends when a profile is strictly preferred to the zone $\left(\operatorname{Pr}_{h} P Z_{i}\right)$, in which case $Z_{i}$ is assigned to class $h+1$.

\subsection{Choice of weighting sets for the criteria family}

The choice of criteria-specific weightings requires the input of expert opinion. Two methods were used to determine such weighting sets. The first consists of holding a meeting of the expert committee and discussing the criteria until a consensus is reached regarding the weight of each criterion. The second, known as the 'cards method' (Arondel and Girardin, 2000; Roy and Figuera, 2002), is well-adapted to ELECTRE-type methods and facilitates communication and discussion between experts. The operating approach consists of associating a card with each criterion. Experts are then individually asked to: sort the criteria from the least important to the most important, with the possibility of placing criteria at the same rank; insert blank cards to indicate the relative importance among criteria from one rank to the next; and specify the ratio of the highest weight to the least weight assigned the criteria. This revised Simos method (Roy and Figuera, 2002) has many advantages, namely preventing criteria from being eliminated by a zero-weight assignment and incorporating the various weightings ascribed by participants as a function of their interests and skills. This method was used to obtain one weighting set for zones with buildings and another set for zones with infrastructures (see Table $4)$. The weight of criterion $j$ is denoted $k_{j}$.

The weights listed in Table 4 demonstrate that the

Table 4

Weighting sets selected by the experts committee, for the prioritisation of zones at risk under buildings and under infrastructures

\begin{tabular}{|c|c|c|c|c|c|c|c|c|c|c|c|c|c|c|}
\hline Criterion & $g_{1.1}$ & $g_{1.2}$ & $g_{1.3}$ & $g_{1.4}$ & $g_{1.5}$ & $g_{2.1}$ & $g_{2.2}$ & $g_{2.3}$ & $g_{2.4}$ & $g_{2.5 .1}$ & $g_{2.5 .2}$ & $g_{2.5 .3}$ & $g_{2.5 .4}$ & $g_{2.5 .5}$ \\
\hline $\begin{array}{l}\text { Weights for zones } \\
\text { with buildings }\end{array}$ & 5 & 1 & 1 & 1 & 5 & 1 & 1 & 20 & 1 & 10 & - & - & - & - \\
\hline $\begin{array}{l}\text { Weights for zones } \\
\text { with infrastructures }\end{array}$ & 5 & 1 & 1 & 1 & 5 & 1 & 1 & 20 & 4 & - & 4 & 4 & 4 & 2 \\
\hline
\end{tabular}


Table 5

Evaluations of zones on each criterion

\begin{tabular}{|c|c|c|c|c|c|c|c|c|c|c|}
\hline \multirow[t]{2}{*}{ Zone } & \multicolumn{10}{|c|}{ Criterion } \\
\hline & $g_{1.1}$ & $g_{1.2}$ & $g_{1.3}$ & $g_{1.4}$ & $g_{1.5}$ & $g_{2.1}$ & $g_{2.2}$ & $g_{2.3}$ & $g_{2.4}$ & $g_{2.5 .1}$ \\
\hline $\mathrm{Z}_{1}$ & 5.8 & 10 & 0 & 20 & 0 & 35 & 2.37 & 6.8 & 3.6 & 20 \\
\hline $\mathrm{Z}_{2}$ & 4.8 & 0 & 40 & 0 & 0 & 70 & 1.28 & 1.83 & 0.2 & 10 \\
\hline $\mathrm{Z}_{3}$ & 9.7 & 10 & 10 & 0 & 30 & 200 & 1.67 & 0.84 & 7.4 & 30 \\
\hline $\mathrm{Z}_{4}$ & 10.4 & 10 & 10 & 10 & 30 & 203 & 1.68 & 0.83 & 9.0 & 20 \\
\hline$Z_{5}$ & 9.7 & 0 & 10 & 0 & 10 & 222 & 1.2 & 0.54 & 1.8 & 20 \\
\hline $\mathrm{Z}_{6}$ & 9.8 & 10 & 0 & 20 & 0 & 50 & 1.27 & 2.54 & 6.7 & 20 \\
\hline $\mathrm{Z}_{7}$ & 12.3 & 0 & 0 & 0 & 30 & 155 & 0.96 & 0.61 & 14.1 & 10 \\
\hline $\mathrm{Z}_{8}$ & 11.2 & 10 & 0 & 0 & 30 & 180 & 0.71 & 0.39 & 6.4 & 20 \\
\hline $\mathrm{Z}_{9}$ & 11.3 & 0 & 40 & 20 & 0 & 115 & 2.18 & 1.89 & 2.5 & 10 \\
\hline $\mathrm{Z}_{10}$ & 11.0 & 10 & 0 & 10 & 30 & 170 & 0.31 & 0.18 & 2.6 & 20 \\
\hline \multicolumn{11}{|l|}{ Profile } \\
\hline $\operatorname{Pr}_{1}$ & 14 & 10 & 40 & 20 & 20 & 110 & 1.8 & 1 & 35 & 30 \\
\hline $\operatorname{Pr}_{2}$ & 10 & 10 & 10 & 10 & 10 & 150 & 1.4 & 0.82 & 20 & 20 \\
\hline $\mathrm{Pr}_{3}$ & 8 & 0 & 10 & 10 & 10 & 190 & 1 & 0.63 & 6 & 20 \\
\hline \multicolumn{11}{|c|}{ Threshold } \\
\hline$Q$ & 0.05 & 0 & 0 & 0 & 0 & 10 & 0.1 & 0.05 & 0.5 & 0 \\
\hline$P$ & 0.1 & 0 & 0 & 0 & 0 & 20 & 0.2 & 0.09 & 1 & 0 \\
\hline Weights & 5 & 1 & 1 & 1 & 5 & 1 & 1 & 20 & 1 & 10 \\
\hline
\end{tabular}

expert committee has assigned considerable importance to both the expected surface deformation $\left(g_{2.3}\right)$ and building vulnerability $\left(g_{2.5 .1}\right)$ criteria, by ascribing weights of 20 and 10, respectively, which represent $43 \%$ and $22 \%$ of total criteria family weight. Such a decision suggests that these two criteria play a determinant role in the choice of the risk class.

Note that a single criterion with a low weight may be sufficient to change the decision made by the 'strongest' criterion in the family, provided it is contradictory and imposes a 'veto' (Roy, 1985; Yu, 1992), as shown below.

\section{Implementation of the 'ELECTRE TRI' method}

This section will describe the prioritisation method for zones at risk through a ten-zone sample (Table 5). In practical terms, the method is capable of handling many more zones; up until now, we have actually applied it on over 300 zones.

All ten zones included in Table 5 contain buildings. Parametric studies have allowed identifying indifference and preference thresholds for each quantitative criterion.

In order to specify the appropriate monitoring system for each zone in Table 5, it is necessary to define entry conditions for risk classes. A statistical data analysis of an assignment sample of 52 zones under buildings and 69 zones under infrastructures helped establish these conditions which have then been validated by the committee of experts.
The ELECTRE TRI method was used in conjunction with the ELECTRE TRI software, Version 2.0 (Mousseau et al., 1999). This software relies upon two procedures for risk class assignment: the pessimistic procedure and the optimistic procedure. The pseudo-disjunctive procedure mentioned above (Section 4.1) corresponds to the optimistic procedure in the software.

The two credibility indices $\sigma\left(\mathrm{Z}_{i}, \mathrm{Pr}_{h}\right)$ and $\sigma\left(\operatorname{Pr}_{h}, \mathrm{Z}_{i}\right)$ were calculated for each of the ten zones and are presented in Table 6 .

These credibility indices are then compared to parameter $\lambda$ (see Section 4.1) which must be greater than 0.5. This value of $\lambda$ means that at least $50 \%$ of the criteria family accredits the entry of the zone $Z_{i}$ into the considered risk class. In practice, the value of $\lambda$ has to be greater than (1-highest weight/total weight), i.e. above 0.57 in our case. With this minimum $\lambda$ value, assignment of a zone to a risk class needs the agreement of more than one criterion within the criteria family (this value prevents the most weighted criterion from being the only one to decide the assignment class). No value of parameter $\lambda$ higher than 0.57 is better than another. In this example, we have tested six values: $0.60,0.65,0.70,0.75,0.80$ and 0.85 .

For purposes of illustration, let's consider zone $\mathrm{Z}_{8}$ and $\lambda=0.65$. We first calculate the credibility indices and then proceed with risk class assignment. The comparison procedure begins with the low profile $\operatorname{Pr}_{3}$ of Class 3. $\mathrm{Z}_{8}$ and $\mathrm{Pr}_{3}$ assume the values $11.2 \mathrm{MPa}$ and 8 MPa on criterion $g_{1.1}$, respectively. From Table 5, we

Table 6

Credibility indices $\sigma\left(\mathrm{Z}_{i}, \operatorname{Pr}_{h}\right)$ and $\sigma\left(\operatorname{Pr}_{h}, \mathrm{Z}_{i}\right)$ for the ten study zones

\begin{tabular}{lllll}
\hline \multicolumn{2}{c}{$\sigma\left(\mathrm{Z}_{i}, \mathrm{Pr}_{h}\right)$} & $\operatorname{Pr}_{3}$ & $\operatorname{Pr}_{1}$ & $\begin{array}{l}\text { Assignment of zones } \\
\text { to risk classes } \\
\sigma\left(\mathrm{Pr}_{h}, \mathrm{Z}_{i}\right)\end{array}$ \\
\hline $\mathrm{Z}_{1}$ & 0.717 & 0.717 & 0.500 & Class 1 \\
& 0.500 & 0.522 & 0.544 & \\
$\mathrm{Z}_{2}$ & 0.500 & 0.478 & 0.478 & Class 1 \\
& 0.522 & 0.522 & 0.544 & \\
$\mathrm{Z}_{3}$ & 0.956 & 0.913 & 0.348 & Class 2 \\
& 0.087 & 0.674 & 0.891 & \\
$\mathrm{Z}_{4}$ & 0.972 & 0.935 & 0.130 & Class 2 \\
& 0.283 & 0.891 & 0.891 & \\
$\mathrm{Z}_{5}$ & 0.565 & 0.456 & 0.000 & Class 4 \\
& 0.891 & 1.000 & 1.000 & \\
$\mathrm{Z}_{6}$ & 0.848 & 0.826 & 0.500 & Class 1 \\
& 0.383 & 0.522 & 0.544 & \\
$\mathrm{Z}_{7}$ & 0.717 & 0.239 & 0.109 & Class 3 \\
& 0.739 & 0.783 & 0.891 & \\
$\mathrm{Z}_{8}$ & 0.500 & 0.456 & 0.130 & Class 4 \\
& 0.739 & 0.783 & 0.891 & \\
$\mathrm{Z}_{9}$ & 0.630 & 0.609 & 0.489 & Class 1 \\
& 0.391 & 0.391 & 0.565 & \\
$\mathrm{Z}_{10}$ & 0.500 & 0.478 & 0.130 & Class 4 \\
& 0.717 & 0.783 & 0.891 & \\
\hline & & & &
\end{tabular}


Table 7

Agreement and disagreement indices for the comparison between $Z_{8}$ and $\operatorname{Pr}_{3}$ on each criterion

\begin{tabular}{|c|c|c|c|c|c|c|}
\hline \multirow[t]{2}{*}{ Criterion } & \multirow{2}{*}{$\begin{array}{l}\text { Weight of } \\
\text { criterion } k_{j}\end{array}$} & \multicolumn{2}{|l|}{$\mathrm{Z}_{8} \mathrm{~S} \mathrm{Pr}_{3}$} & \multicolumn{2}{|l|}{$\mathrm{Pr}_{3} \mathrm{~S} \mathrm{Z}_{8}$} & \multirow{2}{*}{$\begin{array}{l}\text { Relation } \\
\text { between } \mathrm{Z}_{8} \\
\text { and } \mathrm{Pr}_{3}\end{array}$} \\
\hline & & $\begin{array}{l}\text { Agreement } \\
\text { index } c_{j}\end{array}$ & $\begin{array}{l}\text { Disagreement } \\
\text { index } d_{j}\end{array}$ & $\begin{array}{l}\text { Agreement } \\
\text { index } c_{j}\end{array}$ & $\begin{array}{l}\text { Disagreement } \\
\text { index } d_{j}\end{array}$ & \\
\hline$g_{1.1}$ & 5 & 1 & 0 & 0 & 0 & $\mathrm{Z}_{8}>\mathrm{Pr}_{3}$ \\
\hline$g_{1.2}$ & 1 & 1 & 0 & 0 & 0 & $\mathrm{Z}_{8}>\mathrm{Pr}_{3}$ \\
\hline$g_{1.3}$ & 1 & 0 & 0 & 1 & 0 & $\mathrm{Z}_{8}<\mathrm{Pr}_{3}$ \\
\hline$g_{1.4}$ & 1 & 0 & 0 & 1 & 0 & $\mathrm{Z}_{8}<\mathrm{Pr}_{3}$ \\
\hline$g_{1.5}$ & 5 & 1 & 0 & 0 & 0 & $\mathrm{Z}_{8}>\mathrm{Pr}_{3}$ \\
\hline$g_{2.1}$ & 1 & 1 & 0 & 0 & 0 & $\mathrm{Z}_{8}>\mathrm{Pr}_{3}$ \\
\hline$g_{2.2}$ & 1 & 0 & 0 & 1 & 0 & $\mathrm{Z}_{8}<\mathrm{Pr}_{3}$ \\
\hline$g_{2.3}$ & 20 & 0 & 0 & 1 & 0 & $\mathrm{Z}_{8}<\operatorname{Pr}_{3}$ \\
\hline$g_{2.4}$ & 1 & 1 & 0 & 1 & 0 & $\mathrm{Z}_{8} \mathrm{I} \mathrm{Pr}_{3}$ \\
\hline$g_{2.5 .1}$ & 10 & 1 & 0 & 1 & 0 & $\mathrm{Z}_{8} \mathrm{I} \mathrm{Pr}_{3}$ \\
\hline
\end{tabular}

observe that $Z_{8}$ is preferred to $\operatorname{Pr}_{3}$ as far as criterion $g_{1.1}$ is concerned. Thus, the agreement index $c_{1.1}\left(\mathrm{Z}_{8}, \mathrm{Pr}_{3}\right)=1$ and the disagreement index $d_{1.1}\left(\mathrm{Z}_{8}, \mathrm{Pr}_{3}\right)=0$ (see Appendix A). We now proceed in the same manner for all criteria and for the two complementary assertions ' $Z_{8}$ displays a risk at least as high as $\operatorname{Pr}_{3}$ ' $\left(\mathrm{Z}_{8} \mathrm{~S} \mathrm{Pr}_{3}\right)$ and ' $\operatorname{Pr}_{3}$ displays a risk at least as high as $\mathrm{Z}_{8}{ }^{\prime}\left(\mathrm{Pr}_{3} \mathrm{~S} \mathrm{Z}_{8}\right)$ as shown on Table 7.

Since no veto has been used in the present study (see Appendix A), all disagreements are equal to 0 (Table $7)$. The credibility indices $\sigma\left(\mathrm{Z}_{8}, \operatorname{Pr}_{3}\right)$ and $\sigma\left(\operatorname{Pr}_{3}, \mathrm{Z}_{8}\right)$ thereby have the following values:

$\sigma\left(\mathrm{Z}_{8}, \operatorname{Pr}_{3}\right)=c\left(\mathrm{Z}_{8}, \operatorname{Pr}_{3}\right)=\frac{\sum_{j \in F} k_{j} c_{j}\left(\mathrm{Z}_{8}, \mathrm{Pr}_{3}\right)}{\sum_{j \in F} k_{j}}=0.50<0.65$

$\sigma\left(\operatorname{Pr}_{3}, \mathrm{Z}_{8}\right)=c\left(\operatorname{Pr}_{3}, \mathrm{Z}_{8}\right)=\frac{\sum_{j \in F} k_{j} c_{j}\left(\operatorname{Pr}_{3}, \mathrm{Z}_{8}\right)}{\sum_{j \in F} k_{j}}=0.74>0.65$

Consequently, $\operatorname{Pr}_{3}$ is strictly preferred to $Z_{8}$, the procedure is stopped and $Z_{8}$ is than assigned to Class 4 .

To understand how this comparison procedure may proceed with other profiles, let's now consider the example of zone $Z_{1}$. It has been determined that when this zone is compared with the low profile $\mathrm{Pr}_{3}$ of Class 3 , the credibility index $\sigma\left(\mathrm{Z}_{1}, \mathrm{Pr}_{3}\right)=0.72>0.65$, while $\sigma\left(\operatorname{Pr}_{3}, \mathrm{Z}_{1}\right)=0.50<0.65$. Consequently, $\mathrm{Z}_{1}$ can be placed in Class 3. If we were to continue the comparison with the low profile $\mathrm{Pr}_{2}$ of Class 2, the credibility indices would be: $\sigma\left(\mathrm{Z}_{1}, \mathrm{Pr}_{2}\right)=0.72>0.65$ and $\sigma\left(\mathrm{Pr}_{2}, \mathrm{Z}_{1}\right)=$ $0.52<0.65 . Z_{1}$ can thus be placed in Class 2 as well. A comparison between $\mathrm{Z}_{1}$ and the low profile $\operatorname{Pr}_{1}$ of Class 1 reveals that: $\sigma\left(\mathrm{Z}_{1}, \mathrm{Pr}_{1}\right)=0.50<0.65$ and $\sigma\left(\mathrm{Pr}_{1}, \mathrm{Z}_{1}\right)=$
$0.54<0.65 . Z_{1}$ and $\operatorname{Pr}_{1}$ are thereby incomparable and $\mathrm{Z}_{1}$ can then be assigned to Class 1 (according to the pseudo-disjunctive procedure).

By proceeding in the same manner for all zones with $\lambda=0.65$, zones $\mathrm{Z}_{1}, \mathrm{Z}_{2}, \mathrm{Z}_{6}$ and $\mathrm{Z}_{9}$ are assigned to Class 1 , zones $Z_{3}$ and $Z_{4}$ to Class $2, Z_{7}$ to Class 3 , and zones $\mathrm{Z}_{5}, \mathrm{Z}_{8}$ and $\mathrm{Z}_{10}$ to Class 4 .

The robustness of the classification must, however, be demonstrated by analysing the sensitivity to the change of parameter $\lambda$, the weighting sets, the thresholds and profiles (Roy and Bouyssou, 1993). The results from such a study are summarized in Table 8 , which reveals that the classification of zones $\mathrm{Z}_{3}, \mathrm{Z}_{4}$ and $\mathrm{Z}_{10}$ remains insensitive to parameter changes. The classification of other zones oscillates between two successive classes (see Table 8).

We have only shown results for $\lambda=0.65$. If $\lambda$ were ascribed too high a value (e.g. 0.85), the principle of maximum caution would become exacerbated. Under such conditions, most comparisons conducted between zones and profiles would conclude with their incomparability and would assign zones to Class 1 by virtue of the pseudo-disjunctive procedure.

Table 8

Sensitivity analysis for all 10 study zones

\begin{tabular}{lll}
\hline Zone & $\begin{array}{l}\text { Assignment of zone to risk } \\
\text { Class }(\lambda=0.65)\end{array}$ & $\begin{array}{l}\text { Sensitivity } \\
\text { analysis }\end{array}$ \\
\hline $\mathrm{Z}_{1}$ & Class 1 & Classes 1 and 2 \\
$\mathrm{Z}_{2}$ & Class 1 & Classes 1 and 2 \\
$\mathrm{Z}_{3}$ & Class 2 & Stable \\
$\mathrm{Z}_{4}$ & Class 2 & Stable \\
$\mathrm{Z}_{5}$ & Class 4 & Classes 3 and 4 \\
$\mathrm{Z}_{6}$ & Class 1 & Classes 1 and 2 \\
$\mathrm{Z}_{7}$ & Class 3 & Classes 3 and 4 \\
$\mathrm{Z}_{8}$ & Class 4 & Classes 3 and 4 \\
$\mathrm{Z}_{9}$ & Class 1 & Classes 1 and 2 \\
$\mathrm{Z}_{10}$ & Class 4 & Stable \\
\hline
\end{tabular}




\section{Conclusion}

In early risk-related decision-making phases, methods and tools are necessary to manage incomplete, inaccurate and heterogeneous information. However, all this available information must be combined in a rational way capable of assisting the decision-maker in risk prevention efforts (Dikau et al., 1996; Montovani et al., 1996; Soeters and Van Westen, 1996; Wu et al., 1996). Decision-aid methods are helpful in using and formally presenting available information in order to provide decision-makers and users with a common basis for discussing and resolving problems. In the case of the Lorraine iron-mining basin, analysis of the risk due to mining subsidence is a limited-data decision problem, in which the decision consists of choosing appropriate monitoring systems for all zones concerned. The 'ELECTRE TRI' multi-criteria, decision-aid method is of considerable utility in this context for prioritising zones at risk. Analyses have been based on several parameters and are therefore inherently multi-criteria. The ELECTRE TRI approach is based on comparison between study zones and the entry conditions (profiles) of predefined risk classes. This comparison is conducted for each criterion (partial comparisons) and all criteria are then synthesized into a single global conclusion regarding the entry (or non-entry) of a zone into a class. The reliability of the results provided is an important point for further study. The robustness of risk-zoning depends on several factors, including the accuracy of inputs, the definition of profiles and preference thresholds, and the weighting set. Sensitivity analyses are easy to carry out with ELECTRE TRI, which have up until now enabled classifying over 320 zones within the Lorraine iron-mining basin.

\section{Nomenclature}

$\mathrm{Z}_{i}$ : $\quad$ Zone at risk.

S: $\quad$ Means '...displays a risk at least as high as...'.

$\mathrm{Z}_{\mathrm{i}} \mathrm{S} \mathrm{Pr}_{h}$ : Means ' $\mathrm{Z}_{i}$ displays a risk at least as high as $\operatorname{Pr}_{h}$.

$g_{j}$ : $\quad$ Performance function of the criterion $j$. Used to provide a quantitative or qualitative evaluation on this criterion.

$g_{j}\left(\mathrm{Z}_{i}\right)$ : Value of $g_{j}$ on the zone $\mathrm{Z}_{i}$.

$k_{j}: \quad$ Weight of criterion $j$.

$\operatorname{Pr}_{h}$ : Low profile of the class $h$. This profile represents a limit between two successive classes $h$ and $(h+1)$.

$q_{j}$ and $p_{j}$ : Indifference and preference thresholds. Used to take uncertainty into account on the criterion $j$.

$v_{j}$ : $\quad$ Veto threshold on the criterion $j$. Used to allow the criterion $j$ to put a veto on the assignment of a zone into a class.
$\sigma\left(\mathrm{Z}_{i}, \operatorname{Pr}_{h}\right)$ : Credibility index of the assertion $\mathrm{Z}_{i} \mathrm{~S}_{\mathrm{Pr}_{h}}$. Level of confidence of the assertion ' $\mathrm{Z}_{i}$ is at least as risky than $\operatorname{Pr}_{h}$ '.

$\lambda$ : $\quad$ Minimum ratio of criteria required to validate the assertion $\mathrm{Z}_{i} \mathrm{~S} \operatorname{Pr}_{h}$.

\section{Appendix A:}

\section{A.1. Indifference and preference thresholds}

The indifference threshold $q_{j}$ and the preference threshold $p_{j}$ are defined as follows (see Fig. 11):

- If $\left|g_{j}\left(\mathrm{Z}_{i}\right)-g_{j}\left(\operatorname{Pr}_{h}\right)\right|$ is less than $q_{j}$, the difference is considered as insignificant; it can then be stated that zone $\mathrm{Z}_{i}$ and the low profile of class $h, \mathrm{Pr}_{h}$, are indifferent for the given criterion (Roy, 1985; Yu, 1992);

- If $\left|g_{j}\left(\mathrm{Z}_{i}\right)-g_{j}\left(\mathrm{Pr}_{h}\right)\right|$ is greater than $q_{j}$, the difference is considered as significant; if $g_{j}\left(Z_{i}\right)$ is greater than $g_{j}\left(\operatorname{Pr}_{\mathrm{h}}\right)$, it will then be stated that the risk for zone $\mathrm{Z}_{i}$ is strictly greater than that for the low profile of class $h, \operatorname{Pr}_{h}$ (otherwise, the risk for $\operatorname{Pr}_{h}$ is strictly greater than that for $Z_{i}$ ) (Roy, 1985; Yu, 1992);

- If the preference threshold $p_{j}$ is not equal to the indifference threshold $q_{j}$, the interval between these two values represents an ambiguity range over which it is presumed that the risk is higher even though the difference $\left|g_{j}\left(\mathrm{Z}_{i}\right)-g_{j}\left(\mathrm{Pr}_{h}\right)\right|$ cannot be genuinely considered as significant. It will then be stated that the risk for zone $Z_{i}$ is slightly higher than that for the low profile of class $h, \operatorname{Pr}_{h}$ (otherwise, the risk for $\operatorname{Pr}_{h}$ is strictly higher than that for $Z_{i}$ ) (Roy, 1985; Yu, 1992).

By convention, if a zone is indifferent with a low profile in a given class, the zone is assigned to this class; it will be said that the risk class is closed at the bottom.

In ideal cases, where the evaluation of zone $Z_{i}$ on each criterion is between the evaluation of $\operatorname{Pr}_{h}$ and $\operatorname{Pr}_{h-1}$, then $Z_{i}$ is assigned to class $h$. However, this case is rarely encountered (Roy, 1985). This is why we introduce the credibility index.

\section{A.2. Credibility index}

This index is built with all criteria and used to estimate the credibility of the assertion: 'the risk level of $Z_{i}$ is at least as high as that of $\operatorname{Pr}_{h}{ }^{\prime}\left(\mathrm{Z}_{i} \mathrm{~S} \operatorname{Pr}_{h}\right)$ (or 'the risk level of $\operatorname{Pr}_{h}$ is at least as high as that of $Z_{i}$, $\left.\left(\operatorname{Pr}_{h} \mathrm{~S} \mathrm{Z} \mathrm{Z}_{i}\right)\right)$. It is denoted $\sigma\left(\mathrm{Z}_{i}, \operatorname{Pr}_{h}\right)$ (or $\left.\sigma\left(\operatorname{Pr}_{h}, \mathrm{Z}_{i}\right)\right)$ and may be equal to values lying between 0 and 1 (Roy, 1985). When this index equals 0 , the assertion is completely rejected either because no criterion satisfies it or because a criterion is in a position to veto. If the 


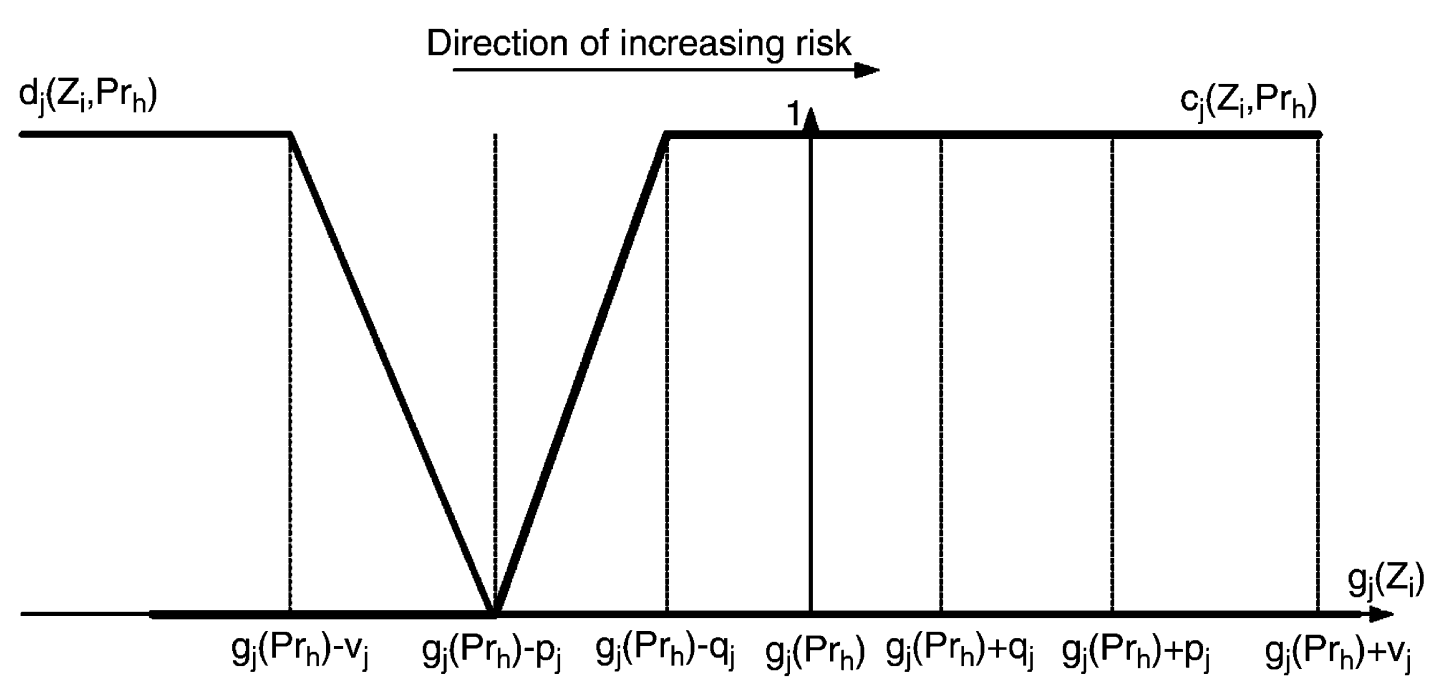

Fig. 12. Partial agreement index $c_{j}$ and disagreement index $d_{j}$.

index equals 1, the assertion is completely accepted, which means that no criterion is in opposition. Between 0 and 1 , the credibility index is based on two other component indices: an agreement index and a disagreement index (see Fig. 12).

The agreement index is a weighted mean of the partial agreement indices and is calculated as follows:

$c\left(\mathrm{Z}_{i}, \operatorname{Pr}_{h}\right)=\frac{\sum_{j \in F} k_{j} c_{j}\left(\mathrm{Z}_{i}, \operatorname{Pr}_{h}\right)}{\sum_{j \in F} k_{j}}$

where $F$ is the set of criteria numbers and $c_{j}$ the partial agreement index on criterion $j$ (Fig. 12).

When the assertion 'the risk for $Z_{i}$ is at least as high as that for $\mathrm{Pr}_{h}{ }^{\prime}$ is rejected for a criterion, the partial agreement index for this criterion is equal to 0 . The agreement index therefore only takes account of those criteria for which this assertion is not rejected.

The partial disagreement index $d_{j}\left(\mathrm{Z}_{i}, \operatorname{Pr}_{h}\right)$ is calculated for criteria that reject the assertion 'the risk for $Z_{i}$ is at least as high as that for $\operatorname{Pr}_{h}$ ' and is defined as follows:

$$
\begin{aligned}
& d_{j}\left(\mathrm{Z}_{i}, \operatorname{Pr}_{h}\right)=1 \\
& -\frac{v_{j}\left(g_{j}\left(\operatorname{Pr}_{h}\right)\right)-\min \left\{g_{j}\left(\mathrm{Z}_{i}\right)-g_{j}\left(\operatorname{Pr}_{h}\right), v_{j}\left(g_{j}\left(\operatorname{Pr}_{h}\right)\right)\right\}}{v_{j}\left(g_{j}\left(\operatorname{Pr}_{h}\right)\right)-\min \left\{g_{j}\left(\mathrm{Z}_{i}\right)-g_{j}\left(\operatorname{Pr}_{h}\right), p_{j}\left(\operatorname{Pr}_{h}\right)\right\}}
\end{aligned}
$$

where $v_{j}\left(g_{j}\left(\mathrm{Pr}_{h}\right)\right)$ denotes a veto threshold for criterion $g_{j}$, related to profile $\operatorname{Pr}_{h}$. When the risk level of zone $\mathrm{Z}_{i}$ for criterion $g_{j}$ is significantly lower than that of profile $\operatorname{Pr}_{h}$ for the same criterion $\left(g_{j}\left(\operatorname{Pr}_{h}\right)-g_{j}\left(Z_{i}\right)>\right.$ $v_{j}\left(g_{j}\left(\operatorname{Pr}_{h}\right)\right)$, the assertion 'the risk level for $\mathrm{Z}_{i}$ is at least as high as that for $\mathrm{Pr}_{h}$ ' must be rejected and $d_{j}\left(\mathrm{Z}_{i}, \mathrm{Pr}_{h}\right)=$ 1 (Roy, 1985). When the assertion is validated on criterion $g_{j}$, this index is equal to 0 . Such a case arises when the difference between the risk level of $Z_{i}$ and that of $\operatorname{Pr}_{h}$ on the considered criterion is less than the preference threshold $p_{j}\left(\operatorname{Pr}_{h}\right)$. Between these two values, the index increases as a function of the value of the difference between the risk level of $Z_{i}$ and that of $\operatorname{Pr}_{h}$ (Yu, 1992) (Fig. 12).

In light of the above discussion, the credibility index is determined as follows:

- $\sigma\left(\mathrm{Z}_{i}, \mathrm{Pr}_{h}\right)=c\left(\mathrm{Z}_{i}, \operatorname{Pr}_{h}\right)$, in the absence of disagreeing criteria;

- $\sigma\left(\mathrm{Z}_{i}, \mathrm{Pr}_{h}\right)=0$, if a disagreeing criterion imposes its veto on the assertion: 'the risk level of $Z_{1}$ is at least as high as that of $\operatorname{Pr}_{h}$ ';

- $\sigma\left(\mathrm{Z}_{i}, \operatorname{Pr}_{h}\right)<c\left(\mathrm{Z}_{i}, \operatorname{Pr}_{h}\right)$, if $\exists j / d_{j}\left(\mathrm{Z}_{i}, \operatorname{Pr}_{h}\right)>c\left(\mathrm{Z}_{i}, \operatorname{Pr}_{h}\right)$.

The credibility index is thus defined as follows:

$\sigma\left(\mathrm{Z}_{i}, \operatorname{Pr}_{h}\right)=c\left(\mathrm{Z}_{i}, \operatorname{Pr}_{h}\right) \prod_{j \in F} \frac{1-d_{j}\left(\mathrm{Z}_{1}, \mathrm{Pr}_{h}\right)}{1-c\left(\mathrm{Z}_{i}, \operatorname{Pr}_{h}\right)}$,

where:

$\bar{F}=\left\{j \in F / d_{j}\left(\mathrm{Z}_{1}, \operatorname{Pr}_{h}\right)>c\left(\mathrm{Z}_{1}, \operatorname{Pr}_{h}\right)\right\}$

\section{A.3. 'ELECTRE TRI' assignment procedures}

Two extreme rationales may be called upon when assigning a zone to a particular risk class: either $Z_{i}$ is assigned to the lowest class given by a criterion or $Z_{i}$ is assigned to the highest class given by a criterion. These two rationales correspond to a principle of caution, which is minimized in the first case and maximized in the second. ELECTRE TRI offers two assignment procedures to attenuate these two extremes, namely a 
pseudo-conjunctive procedure and a pseudo-disjunctive procedure. The pseudo-disjunctive procedure, inspired from the maximum caution rationale, is therefore well adapted to risk prioritisation. According to this procedure, the entry of a zone into a class is accepted if the zone is preferred (higher risk level), indifferent (equivalent risk level) or incomparable (risk level not comparable) to the low profile of the class. With the pseudo-conjunctive procedure, the zone may enter into a class only if it is preferred or indifferent to the low profile of the class. The treatment of incomparability differs from one procedure to the other.

\section{References}

Arondel, C., Girardin, P., 2000. Eur. J. Oper. Res. 127 (3), 467-482.

Deck, O., Al Heib, M., Homand, F., 2003. Eng. Struct. 25 (4), 435-448.

Didier C., 1999, Conférence de la décennie internationale de la prévention des catastrophes naturelles, June 17-19, Paris, Session 2, pp. 85-92.

Dikau, R., Cavallin, A., Jager, S., 1996. Geomorphology 15 (3-4), 227-239.

Ministère de l'Aménagement du Territoire et de l'Environnement, Ministère de l'Equipement, des Transports et du Logement, 1999, Plans de prévention des risques naturels (PPR)-Risques de mouvements de terrains-Guide méthodologique, Paris, La Documentation Française.
Montovani, F., Soeters, R., Van Westen, C.J., 1996. Geomorphology $15,213-225$.

Mousseau V., Slovinski R., Zielniewicz P., 1999, ELECTRE TRI 2.0a-Methodological guide and user's manual, Document du LAMSADE no 111, Paris.

Roy B., Bouyssou D., 1993, Aide multicritère à la décision: Méthodes et cas, Paris, Economica.

Roy, B., Figuera, J., 2002. Eur. J. Oper. Res. 139 (2), 317-326.

Roy B., 1985, Méthodologie multicritère d'aide à la décision, Paris, Economica.

Soeters R., Van Westen C.J., 1996, Slope instability recognition, analysis, zonation, landslides, investigation and mitigation, Special report 247, Transportation Research Board, National Research Council, pp. 129-177.

United Nations, Department of Humanitarian Affairs, Internationallycertified glossary of basic terms related to Disaster Management, 1992.

Varnes D.J., International Association of Engineering Geology Commission on Landslides and Other Mass Movements on Slopes, 1984, Landslide Hazard Zonation: a review of principles and practice, United Nations Economic, Scientific and Cultural Organization, Natural Hazards Series, No. 3, pp. 63-65.

Varoquaux J.A., 1995, Histoire d'une profession, Les Mines de Fer de France, Chambre syndicale des Mines de Fer de France, ISBN 2-907270-50-8.

Whittaker, B.N., Reddish, D.J., 1989. Subsidence: Occurrence, Prediction and Control. Elsevier.

Wu T.H., Tang W.H., Einstein H.H., 1996, Landslide hazard and risk assessment, Investigation and mitigation, Special report 247, Transportation Research Board, National Research Council, pp. 129177.

Yu W., 1992, Aide multicritère à la décision dans le cadre de la problématique du tri, Ph.D. Thesis, Université de Paris-Dauphine. 